\title{
Herança cultural e linguística dos macaenses: considerações em torno das suas origens, evolução e continuidade
}

Mário Pinharanda Nunes ${ }^{1}$

Resumo: Olhamos para a comunidade macaense ${ }^{2}$ e para a sua língua ancestral, o crioulo luso-asiático designado por patuá ou maquista (MAQ), que, enquanto comunidade e idioma minoritárias, veem os seus tradicionais status quo ameaçados. Daremos primeiro uma breve perspectiva diacrónica da formação e evolução desta comunidade e do MAQ; analisaremos a reação da comunidade em momentos de ameaça à continuação da cultura e língua ancestral; e por fim refletiremos acerca da aplicabilidade das atuais estratégias de preservação linguística ao caso do MAQ.

Palavras chave: identidade cultural e linguística; obsolescência e preservação de línguas minoritárias.

\section{Dos primórdios ao séc. XIX}

A expansão marítima portuguesa iniciada no séc. XV chegou à costa do sul da China em meados do séc. XVI. A partir de 1557, a Península onde hoje se situa Macau passa a ser permanentemente habitada por portugueses, no interesse de assegurar o comércio com o lucrativo porto de Cantão e, em última instância, o monopólio da rota marítima da prata do Japão. À semelhança da sua presença em outros pontos do Oriente, ao estabelecerem-se em Macau, os portugueses, sempre em notória minoria, trouxeram consigo gentes de várias origens, nações, línguas, religiões e estatutos. Desta feita, desde cedo a comunidade portuguesa em Macau seria composta por reinóis, portugueses nascidos na Ásia, casados e seus filhos mestiços (ou euroasiáticos), e ainda as mulheres asiáticas daqueles, de origens diversas tais como: Índia, Sri Lanka, Malaca, Java, Sião, Timor. Isto para mencionarmos apenas as principais. Conim \& Teixiera (1998) fornecem detalhados dados acerca dos números da população de Macau desde o seu estabelecimento até finais do séc. XIX, com base em diversas fontes. Relativamente às comunidades de asiáticos e euroasiáticos em Macau desde os seus primórdios, nos census apresentados por aqueles autores, destacam-se os indo-portugueses. De entre estas regiões,

\footnotetext{
${ }^{1}$ Professor do Departamento de Português e pesquisador do Centro de Estudos Luso-Asiáticos da Universidade de Macau.

${ }^{2}$ Empregamos o termo macaense em referência à comunidade de raiz luso-asiática oriunda de Macau. A sua origem provém da mistura sanguínea entre portugueses europeus e asiatizados, lusoasiáticos de outros pontos do Oriente e chineses, promovida pelo estabelecimento dos Portugueses nesta península no sul da China a partir de meados do século XVI.
} 
sobressaem numericamente aqueles classificados como indo-portugueses e como malaios. Sabemos através de Conim \& Teixeira (1998, p. 109) que em 1600, em Macau, a comunidade do primeiro destes dois grupos era já constituída por 600 famílias indo-portuguesas. Outras fontes atestam gentes do subcontinente indiano em Macau desde cedo. Veja-se, a título de exemplo, a referência em Seabra (2006/2007, p. 198) a uma carta do Pe. Francisco de Sousa, de $1563^{3}$, que relata a presença de donzelas e órfãs numa procissão segundo o estilo praticado apenas em Goa. Nos dados do mesmo trabalho, o grupo designado como malaios também apresenta números significativos relativamente à totalidade da população nas primeiras décadas após a fundação desta cidade. Em Pinharanda Nunes (2012: 314) comenta-se que o grupo designado como indo-português não seria exclusivamente composto por gentes provindas apenas do subcontinente indiano, mas antes uma designação abrangente onde cabiam tanto portugueses nascidos na Ásia como também luso-asiáticos oriundos dos sudeste da Ásia e ainda com alguma ligação sanguínea com esse subcontinente. Nos census populacionais disponíveis, figura ainda o grupo de escravos e serviçais jaus, i.e. javaneses (CONIM \& TEIXEIRA, 1998).

O panorama demográfico, que acima se descreveu, apresenta a significativa presença de gentes provindas do subcontinente indiano e do sudeste asiático nos lares cristãos de Macau, desde muito cedo. Partindo do princípio fortemente provável de que todas elas seriam bi- ou trilíngues em crioulo de Malaca, outros crioulos ou pidgins luso-asiáticos e em outras línguas indianas e do sudeste da Ásia ${ }^{4}$, este significativo grupo, ainda que inicialmente algo heterogéneo, deparou-se com um contexto favorável à sua progressiva homogeneização e diferenciação face aos restantes grupos asiáticos em Macau, assim como aos portugueses europeus. Dessa confluência de luso-asiáticos de diversas origens e falando diversas variedades asiáticas de português e outras línguas desses diferentes locais, nasceu a comunidade macaense; com língua e identidade próprias.

A integração da comunidade chinesa na comunidade macaense não terá sido significativa logo desde o início. Para tal, poderão ter contribuído as diferentes matrizes religiosas de uma e de outra comunidade. Assim, o elemento chinês no tecido étnico, cultural e linguístico dos macaenses foi ganhando relevância à medida que os números de cristãos asiáticos e lusoasiáticos vindos das restantes praças portuguesas no Oriente (em especial no sudeste Asiático) foram diminuindo e, por outro lado, os números de conversões de chineses ao catolicismo aumentou. Ordenações administrativas para a governação de Macau emitidas, tanto por parte das autoridades

\footnotetext{
${ }^{3}$ Saliente-se que tinham decorrido apenas 7 anos desde o estabelecimento dos portugueses em Macau, em 1557.

${ }^{4}$ Cf. Pinharanda Nunes (2012, p. 316).
} 
portuguesas, como dos mandarins chineses responsáveis por gerir a presença portuguesa nesta cidade, constituíram mais um fator para a separação de ambas as comunidades nos primeiros tempos. Referimo-nos à divisão entre o bairro cristão (dos portugueses, luso-asiáticos e restantes asiáticos cristãos) e a cidade chinesa até ao séc. XIX; documentada tanto por relatos ocidentais, com chineses. Bocarro (1992 [1635], p. 264), por exemplo, oferece um testemunho da construção do muro (também referenciada como muralha) em redor do setor onde residiam os portugueses e demais cristãos pelas autoridades portuguesas:

Os muros que tem esta cidade estavão quazy acabados por Dom Francisco Mascarenhas, o primeiro capitão-geral que teve [...]. [grifos do autor]

A monografia chinesa do séc. XVII, Ou-Mun-Kei-Leok (YIN \& ZHANG, 2009 [1751], p. 335), faz referência à estrutura divisória inicial, ainda anterior à muralha:

[...] foram levantadas umas cercas nas quatro ruas principais, onde se concentravam as casas [...]. Nas altas palicadas afixaram-se cartazes com os seguintes dizeres: "Temama nossa grandeza e reconheçam a nossa virtude. [grifos do autor]

A mesma monografia menciona, ainda, a posterior demolição da muralha, existindo no séc. XVIII apenas um pequeno muro entre os dois setores da cidade. Os chineses que, segundo esta mesma fonte, já residiam no setor cristão seriam certamente cristãos também e criadagem dos lares portugueses, macaenses e demais cristãos não chineses.

Em Macau havia uma muralha que cercava a cidade bárbara que foi destruída durante a anterior dinastia Ming [...]. Agora só exite um pequeno muro. [...] Os bárbaros residem dentro do muro, onde chineses vivem misturados com eles [...] (YIN \& ZHANG, 2009 [1751], p. 363).

Porém, apesar do desaparecimento da divisória física entre os dois setores da cidade no séc. XIX, a aproximação das comunidades cristã nãochinesa da chinesa (cristã ou não) não foi um processo imediato nem célere. França (1897) relata como os bairros habitados exclusivamente por chineses se mantinham separados dos habitados pelos portugueses e demais cristãos, respeitando ainda o traçado antigo da muralha de outrora.

O cenário acima descrito, indica que, no começo da sua formação, a comunidade macaense extraiu matéria genética, cultural e linguística

18 fragmentum, N. 35, parte I. Laboratório Corpus: UFSM, Out./ Dez. 2012 
primordialmente das fontes portuguesa, (em especial dos asiatizados ${ }^{5}$ ), lusomalaia e indiana. Por outro lado, o crioulo que desta mistura se foi formando, também, naturalmente terá tido, nos primeiros tempos, grande contribuição do crioulo português de Malaca (o Cristang) e de variedades pidgin deste, e variedades da língua malaia - todas estas empregues comumente através sudeste asiático pelos seus respectivos falantes nativos e não nativos para finalidades ligadas à ricas trocas comerciais decorrentes à época (BAXTER, 2009; PINHARANDA NUNES, 2012).

\section{Ameaças à estabilidade}

No séc. XIX, e sobretudo na segunda metade deste, a comunidade macaense, então já plenamente estabelecida como comunidade étnicolinguística própria, pertencente à grande família de comunidades lusófonas, viria a ser confrontada com fatores de mudança. Nos anos 50 desse século, a criação da colónia Britânica na vizinha ilha de Hong Kong, e o recrutamento que as pujantes empresas europeias ali estabelecidas de imediato fizeram junto dos jovens macaenses, abriu novos horizontes a esta comunidade, até então na sua maioria presa a um pequeno território, há muito caído num marasmo económico. Toda a comunidade e, em particular, os seus líderes, cedo entenderam que esta nova colónia vizinha, assim como as demais concessões europeias estabelecidas ao longo da costa chinesa constituíam saídas profissionais ímpares. Entenderam também que, como nativos da região e fluentes em cantonense e alguns mesmo em outros dialetos chineses falados na região (como era o caso do Hokkien), conhecedores dos costumes chineses e do seu modus operandi, poderiam ser peças valiosas nas emergentes empresas europeias ali estabelecidas.

Face à escassez de instituições de ensino público para a comunidade portuguesa e macaense ${ }^{6}$ e à lentidão das autoridades para colmatar dessa lacuna ${ }^{7}$, a comunidade procurou resolvê-lo pelos seus próprios meios. A par da preocupação de instituições de ensino acessíveis a todos os jovens macaenses para a sua formação académica geral, houve ainda a preocupação de lhes propiciar o ensino do inglês e do francês - precisamente pensando no mercado de trabalho então aberto em Hong Kong e nas concessões europeias em portos chineses, sobretudo os de Cantão e de Shangai. De tal forma

\footnotetext{
${ }^{5}$ Empregamos este termo em referência aos portugueses nascidos na Europa ou na Ásia e que se entregaram aos costumes locais, muitas vezes por razão de casamento. Neste caso eram designados como 'casados' (cf. Parágrafo 1).

${ }^{6}$ A primeira escola pública em Macau foi aberta em 1847 - Escola Principal de Instrução Primária.

${ }^{7}$ Desde a fundação de Macau no séc. XVI, a instrução estivera a cargo de ordens religiosas, pouco acessível a certas camadas e ministrada com substancial irregularidade. Cf. Pinharanda Nunes (em preparação) para uma resenha mais aprofundada desta realidade.
} 
estavam conscientes da importância desta medida, que o Senado, composto por um número significativo de membros da comunidade, expôs numa carta ao Governador, datada de 17.02.1847, a necessidade da inclusão do ensino dessas duas línguas no currículo da primeira escola pública que acabara de ser inaugurada. Insatisfeita com a resposta por parte das autoridades, começaram a surgir escolas abertas pela iniciativa pessoal de indivíduos de posses da comunidade portuguesa e macaense. A primeira delas foi a Nova Escola Macaense, fundada em 1862. Tendo como pano de fundo a preocupação do ensino dos seus jovens, foi criada, no seio da comunidade macaense, em 1871 a Associação Para a Instrução dos Macaenses (APIM), que em 1878 abriu a sua primeira escola, a Escola Comercial.

Em Hong Kong, a crescente comunidade emigrada também não descorou o ensino da sua junventude. Por iniciativa de macaenses influentes emigrados abriram-se escolas particulares onde se ensinava português e inglês. Com o aumento rápido da comunidade e o progresso da colónia, passou a haver escolas organizadas e dirigidas por ordens religiosas, onde os macaenses seguiam os seus estudos em língua veicular inglesa; sendo que a comunidade manteve a preocupação de lhes proporcionar aulas de português em horário pós-escolar, como forma de não perderem a ligação a Macau e à matriz cultural portuguesa $^{8}$.

A diáspora macaense do final do séc. XIX terá constituído o primeiro desafio à unidade e à continuidade da comunidade e, consequentemente, da sua língua ancestral. Desafio que soube vencer, mas que não deixou de transformar esta comunidade e afetar o estatuto do MAQ no seio da mesma para sempre. De uma comunidade monolocalizada em Macau, passou a estar dispersa por outros pontos da China, criando-se grupos com novas características adicionadas à matriz original que fora formada em Macau. A progressiva perda do MAQ como língua materna terá sido uma dessas características, mas não necessariamente como consequência direta da emigração, já que também em Macau, pela mesma altura, a comunidade iniciou o processo veloz de corte na transmissão geracional da sua língua ancestral. Em Hong Kong a favor do inglês, e em Macau do português. Pinharanda Nunes (2011), a propósito do estudo da variação na marcação das categorias de tempo, modo e aspeto no MAQ, identifica a geração nascida entre as décadas de 20 e 30 do séc. XX, como a última a aprender e a usar o MAQ como língua materna. A partir dessa geração, o MAQ passou a ser empregue em domínios cada vez mais restritos, como L2, L3 ou simplesmente a partir de

\footnotetext{
${ }^{8}$ Cf. Pinharanda Nunes (em preparação) para uma resenha mais aprofundada das iniciativas tomadas pelas comunidades macaenses de Macau e de Hong Kong em prol da instrução dos seus jovens no final do séc. XIX.
} 
frases feitas e expressões idiomáticas, transmitidas geracionalmente como parte da herança cultural macaense.

No caso da comunidade que permaneceu em Macau, a invasão dos espaços habitualmente ocupados pelo MAQ deveu-se à maior acesso à instrução, que por sua vez abriu mais possibilidades de ingresso em carreiras da função pública que, naturalmente, se encontrava sob controlo português. Esta realidade, aliada ao aumento exponencial da população imigrante chinesa em Macau, a partir das primeiras décadas do séc. XX, terá aproximado a comunidade macaense desta cidade da comunidade portuguesa, sem que com ela se fundisse, nem se confundisse. A progressiva perda da sua língua ancestral, o MAQ, não ditou a perda da sua identidade construída desde o século XVI, em oposição à das restantes comunidades na região. Desta forma, manteve ao longo do séc. XX os seus costumes e tradições (como jogos, celebrações religiosas, récitas humorísticas etc.) e a sua culinária.

Mas o século XX não deixaria de impor desafios à unidade e continuidade da comunidade macaense. A Guerra Sino-japonesa, seguida da $2^{a}$ Guerra Mundial e logo da implantação da República Popular da China em 1949, forçou todas as comunidades de macaenses radicados em cidades portuárias das agora ex-concessões europeias a fugirem. Dipersaram-se numa diáspora agora mais alargada do que aquela que levara a comunidade para Hong Kong no séc. XIX. A maioria voltou para Hong Kong ou Macau, mas houve quem tivesse iniciado uma imigração para os Estados Unidos e Canadá, Austrália e Brasil, entre outros países. A evolução ideológica e política da Republica Popular da China a partir da década de 60 e, sobretudo nos anos 70, instaurou o receio e desconfiança dos propósitos do regime comunista de Pequim e muitos voltaram a optar pela diáspora. Esta vaga foi principalmente para a América do Norte e a Austrália.

Por fim, o séc. XX imporia um desafio final às comunidades que restavam em Macau e Hong Kong: a transferência das respectivas administrações europeias (portuguesa e inglesa) para a China. Neste caso, o êxodo de Hong Kong foi mais significativo do que o de Macau. Embora numerosas famílias em Macau tenham optado por sair antes da transferência em 1999 (algumas das quais entretanto voltaram), a comunidade residente no território que a viu nascer no século XVI, parece ter vacilado menos, ter estado mais confiante no seu futuro, mas também ter sentido que tal mudança política e social podia trazer consigo o perigo da dissolvência da rede identitária que lhes restava. Esta realidade iniciou um processo de autoconsciencialização da necessidade em preservar a identidade própria. Nesse sentido, assistiu-se ao renascer da popular tradição das récitas (muito populares no séc. XIX e início do XX), pela iniciativa do grupo Doci Papiaçam, sob direção do jurista de profissão, Miguel de Senna Fernandes, a partir do final da década de 80. Hoje, este grupo integra anualmente a programação do prestigiado Festival de Artes 
de Macau. Mais recentemente, após a atribuição do estatuto de Património Cultural da Humanidade pela UNESCO a determinados edifícios e monumentos de Macau, Miguel de Senna Fernandes (atual Presidente da Associação dos Macaenses), trabalhando em conjunto com outras figuras de destaque da comunidade, apresentaram candidatura do MAQ e da récita em MAQ ao estatuto de Património Intangível da Humanidade, à UNESCO. Na primeira metade de 2012, o Governo da Região Especial de Macau reconheceu a récita em maquista (ou patuá) como património intangível desta região. Também em 2012, foi criada a Confraria da Gastronomia Macaense, com o objectivo de reunir receitas de família antigas, divulgar e preservar a arte da culinária macaense.

Pela língua ancestral, o MAQ, em Macau, também vêm sendo tomadas algumas iniciativas, embora mais dispersas e menos visíveis: cursos esporádicos de MAQ em diversas associações de macaenses na diáspora; um dicionário maquista - português / inglês (SENNA FERNANDES \& BAXTER, 2004); a primeira tese de doutoramento focando aspectos gramaticais do MAQ (PINHARANDA NUNES, 2011); comunicações em conferências e artigos publicados em revistas académicas (PINHARANDA NUNES \& BAXTER 2004; PINHARANDA NUNES 2008, 2011b, 2012); e como referimos, a candidatura desta língua ao estatuto de património intangível. Também na diáspora, multiplicam-se iniciativas de preservação da identidade cultural e mesmo linguística macaense, promovidas pelas diversas associações, em diferentes locais. É em Vancouver, Toronto, São Francisco, Sydney, Perth, São Paulo, Lisboa que se encontram as Casas de Macau com maior número de sócios e consequentemente mais ativas.

\section{Preservação cultural e linguística: reflexão preliminar}

As características da evolução da comunidade macaense e do uso que faz da sua língua ancestral identificam-na como uma comunidade cuja língua corre sérios perigos de extinção, de acordo com os parâmetros que pesquisadores, ONGs e a Unesco têm adotado para a identificação deste tipo de situações. Tais critérios têm-se baseado essencialmente na escala GIDS (Graded Integrational Disruption Scale) proposta por Fisherman (1991) e adaptada para a EGIDS (Expanded Integrational Disruption Scale) pela UNESCO em 2003. As línguas identificadas como estando em vias de extinção passaram a ser alvo da atenção de académicos, instituições de pesquisa, governos e das próprias comunidades; sendo que o passo seguinte é a busca da sua preservaçcão ou revitalização (nos casos mais extremos). Para tal, há a necessidade de primeiro as documentar a partir dos últimos falantes. Estes dois tipos de intervenção criaram duas novas subdisciplinas dentro da 
linguística que têm vindo a ganhar cada vez mais robustês (cf. HIMMELMANN 1998, 2006; WOODBURY 2003).

Porém, o trabalho de documentaçcão linguística e, sobretudo, de preservação e revitalização de línguas identificadas como ameaçadas de extinção não se tem desenvolvido isento de críticas e ceticismo, tanto por parte de académicos, como das próprias comunidades herdeiras dessas línguas. $\mathrm{O}$ trabalho de documentação de uma língua nas circunstâncias referidas coloca questões éticas, como os detentores dos direitos sobre o material recolhido - o seu arquivo e uso; a escolha de uns falantes e fontes para a documentação em detrimento de outros, etc 9 .

A preservação e revitalização destas línguas também nem sempre decorre pacificamente e começa a levar os próprios académicos nela envolvidos, ou em campos paralelos (antropologia, sociologia e sociolinguística), a questionarem-se quanto à aceitabilidade ética da mesma, face aos direitos das respectivas comunidades sobre o seu destino e a evolução da sua herança cultural e linguística. Heller \& Duchene (2007) duas das vozes mais críticas relativamente à implementação de ações de revitalização linguística, chamam a atenção para o facto de muitas das vezes tais iniciativas preocuparem-se apenas com a língua, não colocando os seus falantes no centro do projeto também. Levantam-se aqui, ainda, questões de direitos dos benefícios de tais acções de preservação: quem se beneficia mais com tais projetos de preservação quando apoiados por governos ou instituições: A comunidade ou os próprios governos e instituições?

Olhando para o caso do MAQ, língua crioula ancestral da comunidade macaense e alvo das atenções de alguns setores dessa comunidade e do governo local com o propósito de lhe conseguir o estatuto de património intangível, apraz-se-nos refletir que o caminho para ações pela sua preservação é delicado. O essencial será que a comunidade, dentro e fora de Macau, expresse o seu desejo quanto aos moldes em que tal preservação deverá ser efetuada. Tal poderá ser realizado através de uma aferição do grau de vitalidade do MAQ em cada um dos polos da comunidade e das respetivas atitudes linguísticas. O contributo dos académicos deverá ser de cariz orientador e esclarecedor, não diretivo e impositivo, respeitando a vontade, ou as vontades, dos herdeiros legítimos do MAQ.

\footnotetext{
${ }^{9}$ Cf. Grinvald (1992) para um levantamento extenso de questões éticas suscitadas pela atividade de documentação de línguas em vias de extinção.
} 


\section{Referências}

BAXTER, A.N. O português em Macau: contacto e assimilação. In Português em Contato, A.M. Carvalho (ed), 277-312. Madrid/Frankfurt: VervuertIberoamericana, 2009.

BOCARro, A. O Livro das Plantas de Todas as Fortalezas, Cidades e Povoações do Estado da Índia Oriental, vol. II. Lisbon: Imprensa Nacional - Casa da Moeda, 1992 [1635].

CONIM, Custódio, N.P.S. and TEIXEIRA, Maria Fernanda Bragança, (1998) Macau e a sua populacao, 1500-2000: aspectos demograficos, sociais e económicos. Macau : Direcção dos Serviços de Estatística e Censos.

FISHMAN, Joshua A. Reversing Language Shift. Clevedon: Multilingual Matters, 1991.

FRANÇA, B. da. Macau e os Seus Habitantes: Relações com Timor. Lisbon: Imprensa Nacional, 1897.

HELLER, M. \& DUCHÊNE, A. Discourses of endangerment: sociolinguistics, globalization and social order. In: DUCHÊNE, A \& HELLER, M (Eds.). Discourse of Endangerment. Interest and Ideology in the Defense of Languages. London, New York: Continuum, 2007.

HIMMELMANN, Nikolaus. Documentary and Descriptive Linguistics. Linguistics 36: 161-195.

PINHARANDA NUNES, M. \& BAXTER, A.N. Os marcadores pré-verbais no crioulo de base lexical portuguesa de Macau. Papia - Revista Brasileira de Estudos Crioulos e Similares 13: 31-46, 2004.

Os Demonstrativos em Maquista: uma análise morfo-sintáctica constrativa. Papia - Revista Brasileira de Crioulos e Similares, 18, UNB, Brasília, 2008.

- Estudo da Expressão Morfo-Sintáctica das Categorias de Tempo, Modo e Aspecto em Maquista. PhD dissertation, University of Macau, 2011a.

. A Representação da Noção de Identidade nos Textos em maquista do séc. XIX. Revista Cultura, Edição Internacional, 35, Instituto Cultural de Macau, Macau, 2011b.

- Traces of superstrate verb inflection in Makista and other AsianPortuguese creoles. In: CARDOSO, Hugo C.; BAXTER, Alan N.; NUNES, Mario Pinharanda (Eds.). Ibero-Asian Creoles Comparative Perspectives. John Benjamins Publishing Company Amsterdam / Philadelphia, 2012. . (em preparação) Socio-historical Factors in Changes on The

Creole Matrix of Makista.

SEABRA, L. Traços da presença feminina em Macau. Campus Social 3-4: 197-208, 2006/2007.

24 fragmentum, N. 35, parte I. Laboratório Corpus: UFSM, Out./ Dez. 2012 
SENNA FERNANDES, M. \& BAXTER, A.N. Maquista Chapado: Vocabulary and Expressions in Macau's Portuguese Creole. Macau: Macau International Institute, 2004.

WOODBURY, Anthony C. Defining documentary linguistics. Language Documentation and Description, Volume 1, Peter K. Austin (ed), 35-51. London: Hans Rausing Endangered languages Project, 2003.

YIN, G. \& ZHANG, R. Breve Monografia de Macau. Macau: Instituto Cultural, 2009 [1751]. 